\title{
Images in Hepatology
}

\section{Recent Onset Dyspnea in a Patient with Cirrhosis of Liver}

$\mathrm{T}$ his patient developed hepatopulmonary syndrome (HPS), which is characterized by a defect in the arterial oxygenation induced by pulmonary vascular dilation in the setting of liver disease; patients of all ages can be affected. ${ }^{1}$ This clinical syndrome has three components: liver disease, pulmonary vascular dilatation, and a defect in oxygenation. ${ }^{1}$ Dyspnea on exertion, at rest, or both is the predominant presenting symptom, usually after years of liver disease. The presence of spider nevi, digital clubbing (this case) or cyanosis suggests HPS. The prevalence of the HPS, including that involving mild stages, ranges between $5 \%$ and $32 \%{ }^{1}$

The diagnostic criteria for HPS include chronic liver disease and/or portal hypertension; an $\mathrm{AaPO}_{2}$ of $\geq 15 \mathrm{mmHg}$ or $\geq 20 \mathrm{mmHg}$ or greater than or equal to the age adjusted value and/or $\mathrm{PaO}_{2} \leq 80 \mathrm{mmHg}$ or $\leq 70 \mathrm{mmHg}$ and pulmonary vascular dilation at contrast-enhanced echocardiography (CEE) or perfusion body scan with ${ }^{99 \mathrm{~m}}$ Technetium-labeled macro-aggregated albumin ( ${ }^{99 \mathrm{~m}}$ TcMAA) ${ }^{2}$

Two techniques are generally used to confirm the intrapulmonary dilation and include transthoracic CEE and ${ }^{99 m}$ TcMAA. ${ }^{2}$ The most common method to detect pulmonary vascular dilation is CEE. During CEE, agitated saline (to produce microbubbles $>10 \mu \mathrm{m}$ in diameter) is injected intravenously in a peripheral vein in the arm to visualize the intrapulmonary shunts. Contrast-enhanced echocardiography is considered to be positive if the microbubbles appear in the left side of the heart four to six beats after they first appear in the right side of the heart. The timing of the appearance of the microbubbles in the left side of the heart makes the distinction between intrapulmonary and intracardiac shunts; with later, the microbubbles appear in the left side of the heart within three beats after they first appear in the right side of the heart. ${ }^{1,2}$

In normal individuals, the macro-aggregates of ${ }^{99 \mathrm{~m}}$ TcMAA are almost completely trapped in the pulmonary circulation. In the presence of cardiac right-to-left shunts or intrapulmonary vascular dilation, the uptake of ${ }^{99 \mathrm{~m}} \mathrm{TcMAA}$ in other organs, such as the brain or the spleen, can be visualized. The extrapulmonary radioactivity to the total body radioactivity ratio during the ${ }^{99 \mathrm{~m}}$ TcMAA body scan gives the estimate of the pulmonary shunt fraction. ${ }^{1,3}$ The pulmonary shunt fraction is increased when the radioactive pulmonary shunt fraction is $>6 \%$; the higher the pulmonary shunt fraction, the more severe the arterial hypoxemia. ${ }^{1,3}$

Liver transplantation is the only successful treatment. ${ }^{4,5}$ Patients with the HPS had a 5-year survival rate of $76 \%$ after liver transplantation, which is not significantly different from those patients without HPS who underwent transplantation. ${ }^{6}$ Other forms of treatment of HPS include oxygen therapy and nitric oxide inhibition. Longterm oxygen therapy may be recommended for symptoms in patients with severe hypoxemia. Administration of $\mathrm{N}(\mathrm{G})$-nitro-L-arginine methyl ester (L-NAME) by aerosol might be useful in the treatment of HPS.

\section{REFERENCES}

1. Rodríguez-Roisin R, Krowka MJ. Hepatopulmonary syndromea liver-induced lung vascular disorder. N Engl J Med 2008;358: 2378-87.

2. Pastor CM, Schiffer E. Therapy insight: hepatopulmonary syndrome and orthotopic liver transplantation. Nat Clin Pract Gastroenterol Hepatol 2007;4:614-21.

3. Abrams GA, Nanda NC, Dubovsky EV, Krowka MJ, Fallon MB. Use of macroaggregated albumin lung perfusion scan to diagnose hepatopulmonary syndrome: a new approach. Gastroenterology 1998;114:305-10.

4. Taillé C, Cadranel J, Bellocq A, et al. Liver transplantation for hepatopulmonary syndrome: a ten-year experience in Paris, France. Transplantation 2003;75:1482-9.

5. Gupta S, Castel H, Rao RV, et al. Improved survival after liver transplantation in patients with hepatopulmonary syndrome. Am J Transplant 2010;10:354-63.

6. Swanson KL, Wiesner RH, Krowka MJ. Natural history of hepatopulmonary syndrome: impact of liver transplantation. Hepatology 2005;41:1122-9. 